\title{
Psoriasis and Cardiovascular Disease: A Narrative Review
}

\author{
Adrian Martinez-Moreno, Jorge Ocampo-Candiani, Veronica Garza-Rodriguez* \\ Servicio de Dermatología, Hospital Universitario "Dr. José E. González", Universidad Autónoma de Nuevo León, Monterrey, Mexico
}

Psoriasis is a chronic, autoimmune, and inflammatory disease that affects $2 \%$ of the world's population. In recent years, it has been demonstrated that psoriasis confers a $25 \%$ increase in relative risk of cardiovascular disease, independent of factors such as hyperlipidemia, smoking, and obesity. The objective of this review was to analyze and describe the association between psoriasis and cardiovascular disease. In this review, we describe the epidemiological association of psoriasis and cardiovascular disease, pathophysiology, mechanisms, and its association with the well-known cardiovascular risk calculators. In addition, we describe diagnostic tools, such as imaging techniques and novel biomarkers, that are useful in the evaluation of atherosclerotic cardiovascular disease. Finally, we present different systemic therapies that are used in patients with psoriasis and their effect on atherosclerotic cardiovascular disease. This article provides an overview of the current literature on psoriasis and cardiovascular risk, which can be useful for primary care physicians in their daily clinical practice.

Keywords: Psoriasis; Cardiovascular Diseases; Biological Therapy; Atherosclerosis; Prevention and Control 


\section{INTRODUCTION}

Psoriasis is a chronic, autoimmune, and inflammatory disease, with a prevalence of $0.09 \%$ to $5.1 \%$ of the world population and an incidence of 60.4 to 140 new cases per $100,000 .{ }^{1,2)}$ Overall, the Caucasian population seems to be the most affected ethnicity. The disease affects all age groups; however, it presents a bimodal distribution, with a high incidence in the third and sixth decades of life. ${ }^{3)}$ Indeed, approximately $75 \%$ patients with this pathology develop symptoms before the age of 40 years. $^{4)}$

Psoriasis confers a high relative risk of cardiovascular (CV) disease in $25 \%$ of patients, independent of factors such as hyperlipidemia, smoking, and obesity, and patients with severe psoriasis have an additional absolute risk of $6.2 \%$ of suffering a major adverse cardiovascular event (MACE) within 10 years of diagnosis in comparison with healthy populations. ${ }^{5,6)}$ The clinical approach to patients with psoriasis should include a comprehensive evaluation, in the context of CV risk stratification and management of $\mathrm{CV}$ risk factors. ${ }^{7)}$

\section{CLASSIFICATION}

Multiple classifications have been proposed in the evaluation of patients with psoriasis. An example includes bimodal age distribution: type I includes patients diagnosed before the age of 40 years and is associated with psoriasis in first-degree relatives, as well as more severe and recurrent behavior and; type II includes patients diagnosed after the age of 40 years. ${ }^{8)}$ According to the body surface area (BSA) affected, the disease can be classified as mild if the affected BSA is less than $2 \%$, moderate if it is between $3 \%$ and $10 \%$, and severe if the effect involves more than $10 \%$ of the BSA. ${ }^{9)}$ According to its morphological characteristics, psoriasis can be classified as plaque, pustular, guttata, and erythrodermic, with the first one being the most common and occurring in $90 \%$ of cases. Other categories are also described according to their distribution pattern, affected anatomic site, and stage of development. $^{10)}$

\section{EPIDEMIOLOGICAL ASSOCIATION BETWEEN PSORIASIS AND CARDIOVASCULAR DISEASES}

The association between psoriasis and MACE has been described for decades. The first study was conducted in 1973, in which the authors observed a two-fold risk between psoriasis and arterial and venous disease. ${ }^{11)}$ Later, multiple studies were developed to evaluate the increased CV risk in patients with psoriasis; all of the studies described new diagnostic and therapeutic pathways in the management of patients with psoriasis. ${ }^{12)}$

In previous studies, Jung et al. ${ }^{13)}$ described a cohort of Korean patients with increased body mass index (BMI), total cholesterol, systolic blood pressure, prevalence of diabetes, obesity, and dyslipidemia at baseline than those of controls. In a longitudinal study, patients with psoriasis showed a higher hazard ratio (HR) for atherosclerotic CV dis- ease (ASCVD) compared with controls after adjusting for several risk factors; moreover, both males and females stratified by sex also revealed a higher HR for patient with psoriasis, indicating that psoriasis is an independent risk factor for an increased incidence of ASCVD in this population. In this same population, males had a greater HR for ischemic heart diseases and angina pectoris than did females; in addition, HR is higher in patients with moderate and severe psoriasis than in patients with mild psoriasis when stratifying by disease severity. Also, ischemic stroke is more common in female than male patients. These authors conclude that psoriasis is related to a higher risk of ischemic CV events in both male and female Korean patients with severe psoriasis than in other patients. ${ }^{13)}$

Data regarding CV implications in elderly patients with psoriasis demonstrate that there is not a higher prevalence of this disease in patients older than 75 years with acute coronary syndrome (ACS) than in controls; this was recently demonstrated in a study by Morici et al., ${ }^{14)}$ in which Italian patients with ACS were compared with controls.

Another interesting implication of psoriasis that must be considered is the fact that it has a substantial impact on quality of life (QOL). Indeed, this disease is associated with an increased incidence of psychiatric illness (62\%), with depression being the most prevalent. Recent data show that depression in patients with psoriasis may be linked to ischemic heart disease and cerebrovascular disease, making depression an independent risk factor for these diseases. ${ }^{15)}$

It has been shown that psoriasis increases mortality via both global and specific causes. In fact, psoriasis increases the relative risk of mortality from 1.12 to 1.52 compared to the general population. Regarding specific causes, CV disease showed an increase in the relative risk of mortality, ranging from 1.05 to 1.38 . Meanwhile, the main non-CV causes of death in patients with psoriasis were liver and kidney diseases. Other causes that were also prevalent were infections, neoplasms, and chronic respiratory disease of the lower airways. ${ }^{16)}$

\section{PATHOPHYSIOLOGY AND MECHANISM OF CARDIOVASCULAR DISEASE IN PSORIASIS}

It is well known that psoriasis is an inflammatory disease in which Th1 lymphocytes activate antigen-presenting cells, Thl cytokines, and $\mathrm{T}$ cells. When evaluating the cytokine profile in psoriasis and comparing it with that in vascular atherosclerotic lesions, an elevation of, both, Th1 and Th17 lymphocytes was observed. This overexpression of cytokines could induce atherogenesis and CV disease. ${ }^{17}$

In psoriasis, lymphocytes release proinflammatory cytokines, such as interleukin (IL)-2 and interferon- $\alpha{ }^{1{ }^{18)}}$ Other proinflammatory cytokines increased in psoriasis and linked to CV morbidity include IL-6, tumor necrosis factor (TNF), C-reactive protein (CRP), E-selectin, and intercellular adhesion molecule 1. Moreover, some cytokines could affect endothelial function and insulin sensitivity. ${ }^{19)}$ In psoriasis, Th17 cells and the expression of IL-17 are increased in skin lesions, related to a proatherogenic state. ${ }^{20,21)}$

It is important to identify the intermediate mechanisms present in 
the inflammatory process. Regulatory $\mathrm{T}$ cell functions are impaired in psoriasis, leading to a reduction in anti-inflammatory effects in atherosclerosis and psoriasis. Macrophages act as proinflammatory cells and play a role in atherosclerosis and vulnerability to plaque in psoriasis. Neutrophils also play a role in atherosclerosis and independently predict endothelial dysfunction, linking psoriasis and CV diseases. ${ }^{22)}$

Some risk factors are shared between psoriasis and CV risk and can exacerbate inflammation in diseases such as those for diabetes, hypertension, smoking, obesity, and dyslipidemia., ${ }^{3,23)}$ Inflammation is a prime factor in the development of atherosclerotic plaques and increases the risk of rupture resulting in the formation of a thrombus. ${ }^{24,25)}$ In inflammatory disorders, there are three characteristics that are commonly seen: accelerated coronary atherosclerosis, atrial fibrillation as a manifestation of atrial myopathy, and ventricular myopathy with a preserved ventricular ejection fraction. Systemic therapy targeting the reduction of adipose tissue mass and inflammation could be beneficial for both psoriasis and CV disease. ${ }^{26)}$

Vitamin D deficiency has been associated with multiple inflammatory and autoimmune diseases, such as type I diabetes, multiple sclerosis, inflammatory bowel disease, and rheumatoid arthritis and could be independent of traditional CV risk factors. ${ }^{27)}$

Reactive oxygen species oxidize lipids, proteins, low-density lipoprotein (LDL), and high-density lipoprotein (HDL), resulting in cell damage in patients with psoriasis. An increased number of cutaneous advanced glycation end products have been correlated with carotid intima-media thickness (CIMT) in patients with psoriasis and could be a factor in premature atherosclerosis. ${ }^{28-30}$ )

Psoriasis is known to be an independent risk factor for CV disease; meanwhile age, BMI, metabolic syndrome, and smoking status have been found to increase the risk of psoriasis. Women with psoriasis have a risk of hypercholesterolemia and hypertension, and overweight women are more susceptible to type 2 diabetes than are women with normal weight. ${ }^{31,32)}$ In addition, as recently demonstrated by Fernández-Armenteros et al., ${ }^{33)}$ patients with psoriasis have a higher prevalence of traditional CV risk factors, such as type 2 diabetes, dyslipidemia, arterial hypertension, obesity, fasting basal glycemia, low HDL cholesterol, hypertriglyceridemia, and increased waist circumference than in patients without psoriasis. Additionally, the authors found a higher prevalence of ischemic heart disease and vascular-cerebral accidents in patients with psoriasis than in those without. ${ }^{33)}$

\section{CARDIOVASCULAR RISK CALCULATORS IN PSORIASIS}

The Framingham risk score (FRS) calculator estimates the 10-year absolute risk of having coronary artery disease. ${ }^{34)}$ Despite the usefulness of this tool, the calculator generally underestimates CV risk by evaluating risk factors individually; this occurs mainly in patients with chronic systemic inflammatory diseases, since patients with traditional risk factors constitute only a small portion of the total risk, and other factors are not included in the CV risk calculator. ${ }^{7,35)}$ In addition, a rela- tionship between severity of the clinical manifestations of psoriasis and its high CV risk has not been found, which indicates that, regardless of the patient's psoriasis area severity index (PASI), a comprehensive approach is needed for patients with psoriasis and CV disease. ${ }^{36)}$

Some studies have made comparisons to assess CV risk in patients with psoriasis. Reports have shown some variations in their results, with most agreeing that $\mathrm{CV}$ risk calculated in patients with psoriasis was comparable to that in the control group; however, in male patients, the FRS was higher than it was in women in both groups, as well as in adults over 60 years of age and patients with a prolonged disease duration. In addition, when stratifying patients according to their PASI, no significant difference was found between patients with increased severity of the disease compared to those who were minimally affected. $^{37,38)}$

In inflammatory diseases, a taskforce provided by the European League Against Rheumatism suggested multiplication by a factor of 1.5 for $\mathrm{CV}$ risk algorithms in patients with inflammatory arthritis. When applied to different CV risk calculators commonly used worldwide, such as the Systematic Coronary Risk Evaluation, FRS, QRISK2 and Reynold's Risk Score, the discriminative ability and calibration in patients with psoriatic arthritis is not improved. ${ }^{39}$

\section{IMAGING IN THE EVALUATION OF CARDIOVASCULAR DISEASE}

Imaging is a useful tool to detect patients at risk of atherosclerosis without clinical symptoms via measurements of the CIMT and the identification of atherosclerotic plaque. One of the tools used is carotid ultrasound, which allows us to evaluate the presence of subclinical atherosclerosis. This tool helped identify subclinical atherosclerosis in patients with psoriasis, which occurs more frequently in patients with severe disease, as calculated by the PASI, with age being the independent risk factor that best predicts carotid intima media thickness. ${ }^{40)}$ Moreover, ultrasound can be used to detect subclinical atherosclerosis in femoral arteries. Gonzalez-Cantero et al. ${ }^{41)}$ demonstrated that femoral atherosclerotic plaque was more prevalent in patients with psoriasis than in those without, and that it was more prevalent than carotid plaque, thereby improving its detection in subclinical stages. These data make ultrasound a low-cost, high-performance technique that allows assessment of atherosclerotic damage in patients with psoriasis.

Coronary microvascular dysfunction (CMD) is characterized by reduced coronary flow reserve, which is not secondary to epicardial coronary artery stenosis, detected by transthoracic Doppler echography. Piaserico et al. recently stated that CMD is associated with severe psoriasis, psoriatic arthritis, hypertension, and disease duration greater than 6 years, suggesting that this technique is a reliable prognostic marker for patients with psoriasis without a history of CV events. ${ }^{42)}$

The perivascular fat attenuation index (FAI) is a recently developed technique that uses computed tomography (CT) to allow physicians to evaluate coronary inflammation using differential mapping of attenuation gradients in pericoronary fat. Elnabawi et al. ${ }^{43)}$ demonstrated a 
reduction in the FAI of patients receiving biologic therapy for moderate to severe psoriasis, making this a novel tool to evaluate the effects of psoriasis therapy for coronary artery disease.

Echocardiography is a widely used imaging tool for evaluating cardiac function. In patients with psoriasis, left ventricular diastolic dysfunction was found in $36.5 \%$ of patients and was associated with an increase in mitral regurgitation compared to a control group in which none of the patients presented this alteration. ${ }^{44)}$

Another imaging technique that provides support in CV evaluations of patients is the level of coronary arterial calcium (CAC). CAC is a marker of subclinical atherosclerosis associated with $\mathrm{CV}$ events. This marker is associated with coronary artery disease in patients with severe psoriasis and is associated with high CAC values, making this technique an innovative tool for the evaluation of asymptomatic $\mathrm{CV}$ disease. $^{45)}$

Few studies have compared both techniques for the evaluation of CV risk in psoriasis. By extrapolating these two techniques in other inflammatory diseases, carotid ultrasound has been found to have a higher sensitivity than CAC has. ${ }^{46)}$

Positron emission tomography with CT using F18-fluorodeoxyglucose (FDG-PET/CT) is used for benign inflammatory diseases due to the increase in glycolytic activity associated with these conditions, as

Table 1. Systemic drugs used in psoriasis

\begin{tabular}{|c|c|c|c|}
\hline Drug & Mechanism of action & Implications in CV effect & Dermatological findings \\
\hline Methotrexate & $\begin{array}{l}\text { Competitive inhibitor of the enzyme } \\
\text { dihydrofolate reductase. }{ }^{54)}\end{array}$ & $\begin{array}{l}\text { Lower risk of CV disease despite homocysteine level, } \\
\text { enhancement of HDLC function, decrease on serum } \\
\text { lipoprotein(a), E-selectin, carotid intima-media } \\
\text { thickness, and femoral intima-media thickness. }{ }^{55-59)}\end{array}$ & $\begin{array}{l}\text { A } 75 \% \text { improvement of PASI in } 35.5 \% \text { of patients } \\
\text { compared with } 18.9 \% \text { of placebo over } 16 \text { weeks. }{ }^{84)}\end{array}$ \\
\hline Cyclosporine & $\begin{array}{l}\text { Inhibition of the cytokine's production } \\
\text { involved in the regulation of T-cell } \\
\text { activation, specifically IL-2. }{ }^{60,61)}\end{array}$ & $\begin{array}{l}\text { Hypertension, alterations in lipid profile. No } \\
\text { improvement in risk of myocardial infraction, stroke, } \\
\text { and CV death. }{ }^{15,62,63)}\end{array}$ & $\begin{array}{l}\text { Improvement and remission in } 80 \% \text { to } 90 \% \text { of patients in } \\
12 \text { to } 16 \text { weeks. }{ }^{61)}\end{array}$ \\
\hline Etretinate & Mechanism not well understood. & High levels of cholesterol and triglycerides. ${ }^{65)}$ & $\begin{array}{l}\text { Significantly reduces the number of pustules in } \\
\text { palmoplantar pustular psoriasis. }{ }^{85)}\end{array}$ \\
\hline Acitretin & Mechanism not well understood. & $\begin{array}{l}\text { Decrease in resistin levels, dose-dependent elevation } \\
\text { of cholesterol and triglycerides. }{ }^{64)}\end{array}$ & $\begin{array}{l}\text { Erythrodermic and pustular psoriasis show great } \\
\text { response to acitretin, with moderate efficacy in chronic } \\
\text { plaque-type psoriasis. }^{86)}\end{array}$ \\
\hline Colchicine & $\begin{array}{l}\text { Inhibits microtubule assembly at } \\
\text { intermediate doses and causes } \\
\text { microtubular depolymerization at } \\
\text { high doses. }\end{array}$ & $\begin{array}{l}\text { Downregulates IL-1 and TNF- } \alpha \text { activity. Decreases the } \\
\text { risk of atrial fibrillation, platelet activation, inhibits } \\
\text { leukocyte-platelet aggregation, and improves } \\
\text { endothelial function. Acts as anti-inflammatory } \\
\text { drug. }{ }^{87)}\end{array}$ & $\begin{array}{l}\text { Doses at } 0.02 \mathrm{mg} / \mathrm{kg} \text { per day for } 2 \text { to } 4 \text { months improves } \\
\text { skin lesions in patients with thin plaques and papules. } \\
\text { There are reports of maintenance of remission in } \\
\text { patients with extensive, chronic, stable plaque-type } \\
\text { psoriasis. }^{66)}\end{array}$ \\
\hline Briakinumab & IL-12 and IL-23 inhibitor. & $\begin{array}{l}\text { No difference compared to the placebo group. } \\
\text { Increased risk of MACE death in patients with two or } \\
\text { more CV risk factors. }^{76)}\end{array}$ & $\begin{array}{l}\text { A dose of } 100 \text { mg every } 4 \text { weeks shows significant } \\
\text { improvement in QOL, work productivity, and resolution } \\
\text { of lesions. }{ }^{88)}\end{array}$ \\
\hline Ustekinumab & IL-12 and IL-23 inhibitor. & $\begin{array}{l}\text { Decreases inflammation in liver, spleen, and aorta in } \\
\text { patients with improvement of cutaneous lesions. } \\
\text { Could increase risk of MACE. }{ }^{73-75)}\end{array}$ & $\begin{array}{l}\text { PASI-75 at week } 12 \text { in more than } 50 \% \text { of the patients. } \\
\text { Stable clinical response for } 3 \text { years. }{ }^{89)}\end{array}$ \\
\hline Guselkumab & IL-23 inhibitor. & Alters glucose and lipid metabolism. ${ }^{73)}$ & $\begin{array}{l}\text { PASI-75 in all patients who received } 300 \text { mg single } \\
\text { subcutaneous dose. Clinical response maintained over } \\
24 \text { weeks. }^{90)}\end{array}$ \\
\hline Adalimumab & $\begin{array}{l}\text { Humanized anti-TNF monoclonal } \\
\text { antibody. }{ }^{90)}\end{array}$ & $\begin{array}{l}\text { Contraindicated in heart failure, reduces CRP, vascular } \\
\text { endothelial growth factor, Th17, resistin, IL-6, TNF, } \\
\text { glycoprotein acetylation, retinol binding protein } 4 . \\
\text { Improves endothelial function. }{ }^{21,67-70)}\end{array}$ & $\begin{array}{l}\text { Rapid response, significant improvement in } 4 \text { weeks. } \\
\text { Maintenance of response for } 32 \text { weeks. Improvement } \\
\text { in health-related-Q0L. }{ }^{92)}\end{array}$ \\
\hline Etanercept & $\begin{array}{l}\text { Human tumor necrosis factor } \\
\text { receptor p75 Fc fusion protein. }{ }^{90)}\end{array}$ & $\begin{array}{l}\text { Improves vascular function, reduces CRP, enhances } \\
\text { insulin sensitivity. }{ }^{71,72)}\end{array}$ & $\begin{array}{l}\text { Efficacy in patients with moderate-to-severe psoriasis } \\
\text { with well-established safety and tolerability profile. } \\
\text { Excellent maintenance of response after dose } \\
\text { reduction. }{ }^{91)}\end{array}$ \\
\hline Secukinumab & IL-17A antagonist. & Anti-inflammatory treatment reduces CV effect. ${ }^{77,78)}$ & $\begin{array}{l}\text { PASI-75 in } 82 \% \text { of patients receiving } 150 \text { mg every } 4 \\
\text { weeks. }^{93)}\end{array}$ \\
\hline Ixekizumab & IL-17A antagonist. & $\begin{array}{l}\text { No decrease of total cholesterol, LDLC, HDLC, very } \\
\text { LDLC, triglycerides, apolipoprotein A1/B, fasting } \\
\text { glucose, systolic, or diastolic blood pressure. Reduces } \\
\text { CRP. }^{79)}\end{array}$ & $\begin{array}{l}\text { PASI-75 in } 82 \% \text { of the patients who received } 75 \mathrm{mg} \text { at } \\
\text { weeks } 0,2,4,8,12 \text {, and } 16 .{ }^{93} \text { ) }\end{array}$ \\
\hline Brodalumab & $\begin{array}{l}\text { Antagonizes the IL-17 pathway by } \\
\text { binding to IL-17RA. }\end{array}$ & MACE events lower than 0.4 per 100 patients-year. ${ }^{80,81)}$ & $\begin{array}{l}\text { Improvement of PASI-75 in } 82 \% \text { of patients receiving } \\
210 \text { mg at weeks } 0,1,2,4,6,8 \text {, and } 10 . .^{93}\end{array}$ \\
\hline Canakinumab & $\| \mathrm{L}-1 \beta$ inhibitor. & $\begin{array}{l}\text { Lowers CRP, reduction of MACE, CV mortality. No } \\
\text { effects on HDLC. }{ }^{82,83)}\end{array}$ & $\begin{array}{l}\text { Case reports with this drug. Immediate response in } \\
\text { palmoplantar pustular psoriasis using } 300 \text { mg every } \\
4 \text { weeks in combination with cyclosporine. }{ }^{94)}\end{array}$ \\
\hline
\end{tabular}

CV, cardiovascular; HDLC, high-density lipoprotein cholesterol; PASI, psoriasis area severity index; IL, interleukin; TNF, tumor necrosis factor; MACE, major adverse cardiac events; QOL, quality of life; PASI-75, 75\% reduction of psoriasis area severity index; CRP, C-reactive protein; LDLC, low-density lipoprotein cholesterol. 
well as for visualizing the arterial inflammation that occurs in these diseases. In patients with psoriasis, an increase in arterial, hepatic, and psoriatic lesions has been demonstrated by using the FDG-PET/CT technique. In addition, in patients diagnosed with moderate or severe disease, there is an increase in arterial and hepatic inflammation, making this a tool that can be used for the detection of subclinical atherosclerosis. $^{47-49)}$

\section{NOVEL BIOMARKERS}

Biomarkers are useful in the evaluation of systemic inflammation in psoriasis. N-terminal pro B-type natriuretic peptide (NT-proBNP) is an inactive hormone that is derived secondary to the breakdown of BNP, which is produced by cardiomyocytes secondary to increased wall tension. NT-proBNP has been used to evaluate CV disease; indeed, in patients with psoriasis, this inactive hormone is increased compared to healthy controls, due to the high risk of CV disease in affected patients. $^{50)}$

Homocysteine is an amino acid that has been widely used in inflammatory diseases. Patients with severe psoriasis have higher levels of homocysteine than those in patients with mild psoriasis, which correlates with the BSA affected but not with the psoriasis activity score index. $^{51)}$

Galectin-3 (Gal-3) is a protein that is produced by macrophages, eosinophils, and epithelial cells. Proinflammatory processes, including psoriasis, increase Gal-3 levels; moreover, in skin lesions, Gal-3 is absent in the epidermis. Patients with psoriasis have higher levels of Gal3 than in healthy controls, leading to enhanced profibrotic activity. ${ }^{52)}$

\section{IMPLICATIONS OF SYSTEMIC TREATMENT IN CARDIOVASCULAR DISEASE}

For many years, there was a theory that anti-inflammatory treatment

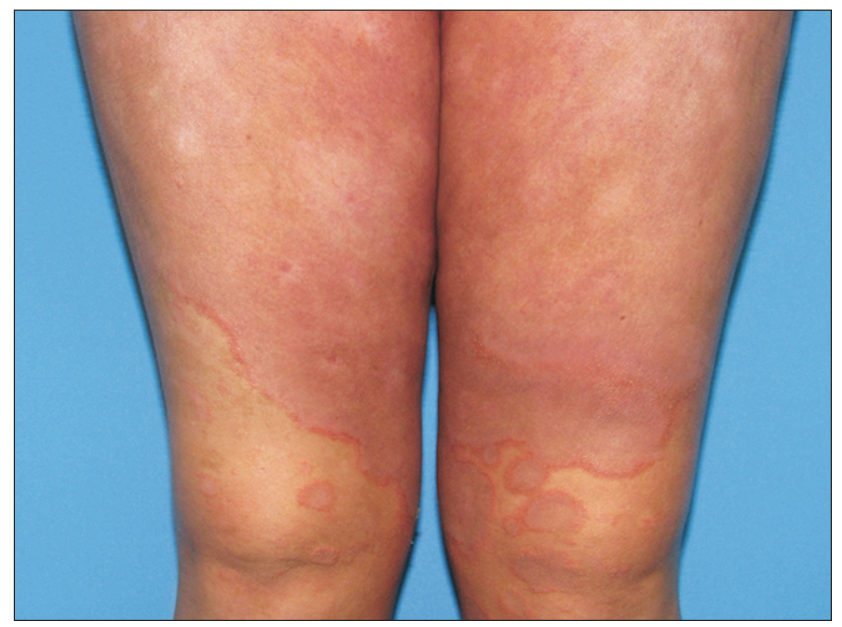

Figure 1. Patient with erythrodermic psoriasis, with psoriasis area severity index of 23.5. Written informed consent for publication of this image was obtained from the patient. in psoriasis decreased the risk of MACE. ${ }^{53)}$ Subsequently, multiple studies evaluating the efficacy of systemic therapy in reducing CV risk have been developed. Table 1 shows different systemic therapies, their mechanism of action, implications in CV effect, and dermatological findings. ${ }^{15,21,54-94)}$

Methotrexate is a drug used as a first-line treatment in psoriasis. ${ }^{54)}$ This drug is one of the most accessible systemic therapies in terms of cost and could be used by primary care physicians (PCP). Patients undergoing treatment with methotrexate have a lower risk of CV disease than in other patients, and this reduction is greater in patients with low cumulative doses of the treatment, with a relative risk of 0.73 and a HR of 0.42 . Additionally, the added use of folic acid, which prevents anemia in patients with methotrexate, contributes to the reduction of this risk, specifically cerebrovascular disease. ${ }^{55-58)}$ Previous studies have been performed in patients with rheumatoid arthritis and concomitant plaque psoriasis, in which the carotid-intima media thickness and femoral intima-media thickness were reduced in patients undergoing this disease-modifying anti-rheumatic drug (DMARD) therapy with 20 mg per week of methotrexate compared to those in patients prescribed with lower doses or different DMARDs, such as cyclosporine or biologics. $^{59)}$

When patients do not respond to topical therapies or methotrexate treatment, they should be referred to a dermatologist. There are several other therapies that could be used for patients with psoriasis.

Cyclosporin is a common drug used as treatment for moderate to severe psoriasis. ${ }^{60,61)}$ Due to the widely known implications and side effects that cyclosporine has, treatment with this drug should be monitored by a dermatologist. Treatment of psoriasis with cyclosporine has some adverse effects that may increase CV risk in patients; in addition, patients with a high BMI are less likely to show improvement when using this drug. ${ }^{62,63)}$ It is recommended that cyclosporin should be used for a short amount of time, maximum a year, and a change to other systemic therapies should be considered when skin lesions have

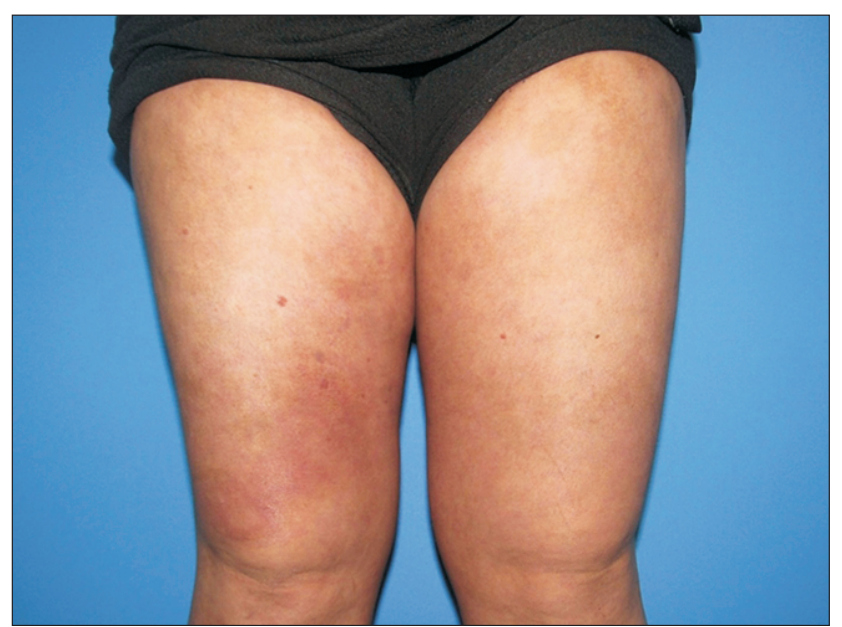

Figure 2. Patient with erythrodermic psoriasis, 10 weeks after initiation of cyclosporin treatment. Psoriasis area severity index of 1.3. Written informed consent for publication of this image was obtained from the patient. 
healed. ${ }^{15)}$ Figures 1 and 2 illustrate a patient using cyclosporin before and after treatment.

Retinoids increase triglycerides and cholesterol levels, and change HDL cholesterol to LDL cholesterol. Acitretin is associated with a decrease in resistin levels and dose-dependent elevation of cholesterol and triglyceride serum parameters; however, this effect could be altered with diet and changes in dosage ${ }^{64)}$ On the other hand, use of etretinate was associated with high cholesterol and triglyceride levels, as previously stated; however, this increase is not associated with a greater CV risk with prolonged use of this drug. ${ }^{65)}$

Colchicine improves psoriasis lesions and is beneficial as a maintenance therapy after lesions have healed. ${ }^{66)}$ This drug has been studied for its effects in CV diseases, showing that low doses prevent CV events in patients with stable coronary disease. ${ }^{95,96)}$

A new treatment model for psoriasis is biological therapy, which is classified into three main groups: $\mathrm{T}$ lymphocyte modulating agents, such as alefacept and efalizumab; inhibitors of TNF- $\alpha$, including adalimumab, infliximab, and etanercept; and inhibitors of the IL-12 and IL23 pathways, such as ustekinumab and briakinumab. ${ }^{97)}$ In addition to using the previously mentioned pathways, treatment was added that involves the IL-17 pathway, such as secukinumab, ixekizumab, and brodalumab or guselkumab, which is against IL-23. ${ }^{98)}$ Figures 3 and 4 illustrate a patient using secukinumab before and after treatment.

Although some studies indicate that the use of TNF inhibitors, antiIL-12/23, and anti-IL17A have no impact on the risk of MACE, it has recently been shown that biological therapy reduces the growth of non-calcified plaque, modifying the morphology of coronary plaque; therefore, it is necessary to evaluate each of these groups in detail to improve evaluation, as well as clinical and therapeutic decisions. ${ }^{99)}$

Inhibitors of TNF- $\alpha$ reduce CRP, vascular endothelial growth factor, and Th17; in addition, they block the differentiation of CD4+ T lymphocytes to Th1, Th17, and Th22, and the subsequent release of IL17A, IL-17F, and IL-22. ${ }^{20)}$ Adalimumab is contraindicated in patients

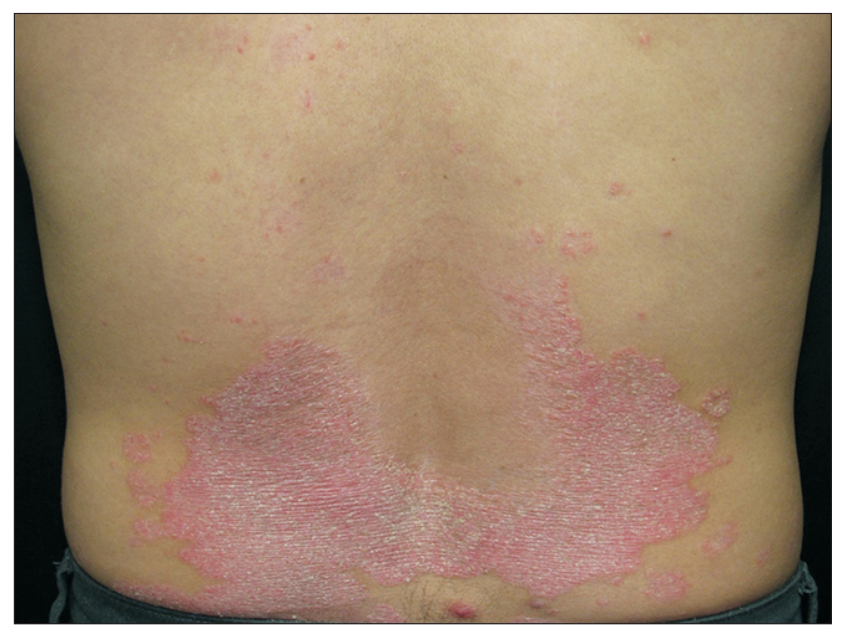

Figure 3. Patient with plaque psoriasis, with psoriasis area severity index of 12.8 . Written informed consent for publication of this image was obtained from the patient. with moderate to severe heart failure; however, inhibitors of TNF- $\alpha$ improve endothelial function by reducing the risk of myocardial infarction. ${ }^{21,67)}$ One year of treatment with this drug has also been shown to decrease the levels of IL-6 and TNF, and the acetylation of glycoproteins. ${ }^{69)}$ Retinol binding protein 4 is a retinol transporter protein that is linked to subclinical atherosclerosis, as it is correlated with the CIMT, and a reduction in the level of this protein occurs during treatment with TNF inhibitors. ${ }^{70,71,100)}$ On the other hand, etanercept improves vascular function by reducing CRP and improving insulin resistance. $^{71,72)}$

Among the inhibitors of IL-12 and IL-23, briakinumab showed no significant difference in MACE compared to a placebo group. With respect to ustekinumab, a 5-year follow-up of more than 12,000 patients with psoriasis did not reveal any CV disease. Additionally, guselkumab does not appear to alter the metabolism of glucose and lipids. ${ }^{73)}$

IL-12 and IL-23 have been implicated as potential factors of atherogenesis, since atherosclerotic plaques contain monocytes producing IL-12, as well as increased cytokines induced by IL-23. ${ }^{20,74)}$ Many of the patients who are recruited in these studies have a high number of $\mathrm{CV}$ risk factors, such as diabetes mellitus, hypertension, hyperlipidemia, obesity, and smoking, which must be considered when deciding which therapy to use. On the other hand, treatment with ustekinumab decreases systemic inflammation. ${ }^{75)}$ Other studies have shown that ustekinumab increases CV risk of MACE in patients with psoriasis. However, overall analysis suggests that this biological agent neither beneficially nor harmfully affects CV events. ${ }^{20)}$ With respect to briakinumab, the appearance of multiple deaths associated with MACE have been reported in a clinical trial, with an increased risk of such events in patients with two or more CV risk factors. ${ }^{76)}$ However, another study did not show a statistically significant difference when comparing these events with those of a placebo group. For these reasons, definite conclusions could not be made concerning briakinumab and the high risk of MACE events.

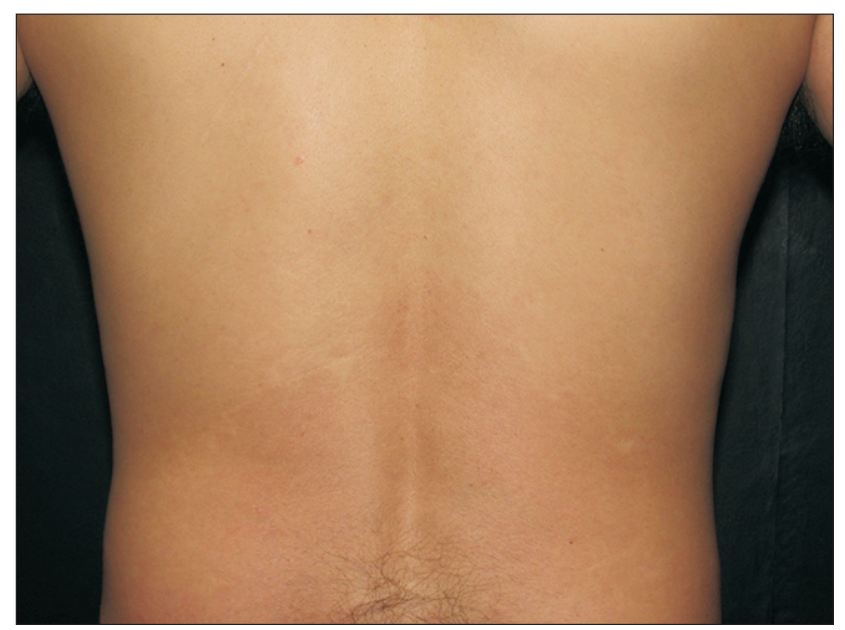

Figure 4. Patient with plaque psoriasis, 8 weeks after initiation of secukinumab treatment. Psoriasis area severity index of 0.4 . Written informed consent for publication of this image was obtained from the patient. 
The effect of treatment with inhibitors of IL-17A on vascular inflammation is still unclear; however, analyses of patients using secukinumab support the idea that this inflammatory treatment decreases the CV effect in patients with moderate to severe psoriasis treated with a 300 mg dose when low rates of MACE are found. ${ }^{77,78)}$ Ixekizumab has not been demonstrated to have a substantial effect on reducing parameters with a CV impact. ${ }^{79)}$ On the other hand, brodalumab has not been shown to cause major CV events compared to ustekinumab in patients who have low levels of MACE, i.e., less than 0.4 events per 100 patientyears. ${ }^{80,81)}$

Canakinumab has been approved for use in autoinflammatory diseases, such as rheumatoid arthritis, periodic syndrome associated with cryopyrin, and multisystem inflammatory disease of neonatal onset, and has also been reported to be effective in diseases such as pustular psoriasis. Patients who have used canakinumab have achieved lower concentrations of CRP, leading to a significant reduction in MACE, CV mortality, and any other cause of death, despite having no effect on HDL cholesterol. ${ }^{82,83)}$ In addition, Ridker et al. ${ }^{101)}$ demonstrated these same effects when using a subcutaneous $150 \mathrm{mg}$ posology every 3 months; however, another study conducted an evaluation of the area of the carotid wall and the aortic distensibility, and no difference was found compared to a placebo group. ${ }^{101,102)}$

\section{ROLE OF THE PRIMARY CARE PHYSICIAN: MANAGEMENT, CONTROL, AND PREVENTION OF CARDIOVASCULAR DISEASE}

Table 2 shows a series of recommendations that PCP should follow for the comprehensive management, control, and prevention of CV disease in patients with psoriasis. ${ }^{68,69)} \mathrm{A}$ complete clinical history should be developed with a focus on comorbidities, such as hypertension, diabetes mellitus, and dyslipidemia. Blood pressure, BMI, and waist circumference should be reevaluated at every 2 years. It is also recommended that serum lipoprotein, glucose, and glycosylated hemoglobin tests be performed at every 5 years, or every 2 years if the patient has a positive hereditary family history or diabetes mellitus. Some guidelines even recommend a biannual evaluation in patients with systemic therapy or prolonged use of topical treatments. Additional recommendations include smoking cessation, moderation of alcohol intake, and 90 minutes of exercise per week..$^{103,104)}$

Table 2. Approach in the management of psoriasis

\begin{tabular}{cc}
\multicolumn{1}{c}{ Recommendations } \\
\hline 1 & Clinical history focusing on arterial hypertension, DM, and dyslipidemia \\
2 & Monitor blood pressure, body mass index, and waist circumference every \\
& 2 years \\
3 & Serum lipoprotein, serum glucose, and glycosylated hemoglobin every \\
& 5 years, or every 2 years if family history or personal history of DM \\
4 & Biannual evaluation in patients with systemic or prolonged topical therapy \\
5 & Smoke cessation, moderate alcohol intake, exercise 90 minutes per \\
& week.
\end{tabular}

$\mathrm{DM}$, diabetes mellitus.
CV risk should be evaluated and managed in patients with psoriasis. Recent studies suggest that hypertension and dyslipidemia are underdiagnosed and undertreated, mainly due to a combination of suboptimal adherence to treatment recommendations and inadequate treatment. Other factors that have been proposed as possible explanations of these gaps between suboptimal diagnosis and inadequate treatment are unawareness of $\mathrm{CV}$ disease, treatment focused on active disease, unknown CV prevention possibilities, and CV disease therapeutic guidelines. ${ }^{105)}$ In the evaluation and management of patients with psoriasis, stratifying CV risk could contribute to the prevention of $\mathrm{CV}$ morbidity and mortality, and could guide the PCP and the dermatologist to choose the best therapy for each patient.

PCP are cornerstones in the prevention and control of CV disease in psoriasis. Increasing the awareness of patients and health workers is an important step in improving patients' CV risk. Semb and Rollefs$\operatorname{tad}^{106)}$ suggested that official programs for educating patients and health workers should be implemented to lower CV risk in patients with psoriasis and psoriatic arthritis. PCP in their outpatient clinics, along with non-physician health workers, must make a joint effort to enhance patient communication, thereby contributing to CV disease control and prevention. ${ }^{106)}$

Multiple studies have shown an association between psoriasis and nutritional effects on CV risk. The Mediterranean diet is a source of antioxidants and monounsaturated fatty acid compounds with antiinflammatory properties and is associated with a lower CV risk. Indeed, PASI, BSA, and physician global assessment levels are lower in patients that adhere to this dietary regimen than in other patients; moreover, patients with severe psoriasis have a low adherence to a Mediterranean diet. ${ }^{107,108)}$

\section{CONCLUSION}

Psoriasis is a chronic and inflammatory disease associated with multiorgan and CV disease. An integrated evaluation and multidisciplinary approach are necessary to increase the QOL and life expectancy of patients with psoriasis. The role of the PCP is to choose the best treatment for decreasing, both, skin lesions and atherosclerotic damage caused by this condition, and referring the patient to the dermatologist when they do not respond to first-line treatment. Also, the PCP must educate the patients and their work team to enhance the communication between the patient and the physician.

\section{CONFLICT OF INTEREST}

No potential conflict of interest relevant to this article was reported.

\section{ORCID}

Adrian Martinez-Moreno: https://orcid.org/0000-0002-6348-6170

Jorge Ocampo-Candiani: https://orcid.org/0000-0002-0213-0031

Veronica Garza-Rodriguez: https://orcid.org/0000-0002-5496-3262 


\section{REFERENCES}

1. Dowlatshahi EA, van der Voort EA, Arends LR, Nijsten T. Markers of systemic inflammation in psoriasis: a systematic review and metaanalysis. Br J Dermatol 2013;169:266-82.

2. Michalek IM, Loring B, John SM. A systematic review of worldwide epidemiology of psoriasis. J Eur Acad Dermatol Venereol 2017;31: 205-12.

3. Neimann AL, Shin DB, Wang X, Margolis DJ, Troxel AB, Gelfand JM. Prevalence of cardiovascular risk factors in patients with psoriasis. J Am Acad Dermatol 2006;55:829-35.

4. Johnson MA, Armstrong AW. Clinical and histologic diagnostic guidelines for psoriasis: a critical review. Clin Rev Allergy Immunol 2013;44:166-72.

5. Lockshin B, Balagula Y, Merola JF. Interleukin 17, inflammation, and cardiovascular risk in patients with psoriasis. J Am Acad Dermatol 2018;79:345-52.

6. Mehta NN, Yu Y, Pinnelas R, Krishnamoorthy P, Shin DB, Troxel AB, et al. Attributable risk estimate of severe psoriasis on major cardiovascular events. Am J Med 2011;124:775.

7. Eder L, Chandran V, Gladman DD. The Framingham risk score underestimates the extent of subclinical atherosclerosis in patients with psoriatic disease. Ann Rheum Dis 2014;73:1990-6.

8. Naldi L, Gambini D. The clinical spectrum of psoriasis. Clin Dermatol 2007;25:510-8.

9. Yeung H, Takeshita J, Mehta NN, Kimmel SE, Ogdie A, Margolis DJ, et al. Psoriasis severity and the prevalence of major medical comorbidity: a population-based study. JAMA Dermatol 2013;149:1173-9.

10. Raychaudhuri SK, Maverakis E, Raychaudhuri SP. Diagnosis and classification of psoriasis. Autoimmun Rev 2014;13:490-5.

11. McDonald CJ, Calabresi P. Occlusive vascular disease in psoriatic patients. N Engl J Med 1973;288:912.

12. Samarasekera EJ, Neilson JM, Warren RB, Parnham J, Smith CH. Incidence of cardiovascular disease in individuals with psoriasis: a systematic review and meta-analysis. J Invest Dermatol 2013;133:23406.

13. Jung KJ, Kim TG, Lee JW, Lee M, Oh J, Lee SE, et al. Increased risk of atherosclerotic cardiovascular disease among patients with psoriasis in Korea: a 15-year nationwide population-based cohort study. J Dermatol 2019;46:859-66.

14. Morici N, Ferri LA, Alicandro G, Tortorella G, Tondi S, Vitrella G, et al. Psoriasis and the risk of acute coronary syndrome in the elderly. Int J Cardiol 2018;273:44-6.

15. Hu SC, Yuan SF, Chen GS, Tu HP. Increased incidence of ischaemic heart disease and cerebrovascular disease in psoriasis patients with depression: a nationwide retrospective cohort study. J Eur Acad Dermatol Venereol 2019;33:1547-54.

16. Dhana A, Yen H, Yen H, Cho E. All-cause and cause-specific mortality in psoriasis: a systematic review and meta-analysis. J Am Acad Dermatol 2019;80:1332-43.

17. Hu SC, Lan CE. Psoriasis and cardiovascular comorbidities: focusing on severe vascular events, cardiovascular risk factors and implications for treatment. Int J Mol Sci 2017;18:2211.

18. Spah F. Inflammation in atherosclerosis and psoriasis: common pathogenic mechanisms and the potential for an integrated treat- ment approach. Br J Dermatol 2008;159 Suppl 2:10-7.

19. Mahyoodeen NG, Crowther NJ, Tikly M. Double trouble: psoriasis and cardiometabolic disorders. Cardiovasc J Afr 2018;29:189-94.

20. Caiazzo G, Fabbrocini G, Di Caprio R, Raimondo A, Scala E, Balato N, et al. Psoriasis, cardiovascular events, and biologics: lights and shadows. Front Immunol 2018;9:1668.

21. Shaaban D, Al-Mutairi N. The effect of tumor necrosis factor inhibitor therapy on the incidence of myocardial infarction in patients with psoriasis: a retrospective study. J Dermatolog Treat 2018;29:3-7.

22. Sajja AP, Joshi AA, Teague HL, Dey AK, Mehta NN. Potential immunological links between psoriasis and cardiovascular disease. Front Immunol 2018;9:1234.

23. Kremers HM, McEvoy MT, Dann FJ, Gabriel SE. Heart disease in psoriasis. J Am Acad Dermatol 2007;57:347-54

24. Rudd JH, Warburton EA, Fryer TD, Jones HA, Clark JC, Antoun N, et al. Imaging atherosclerotic plaque inflammation with $[18 \mathrm{~F}]$-fluorodeoxyglucose positron emission tomography. Circulation 2002;105: 2708-11.

25. Hansson GK. Inflammation, atherosclerosis, and coronary artery disease. N Engl J Med 2005;352:1685-95.

26. Packer M. Epicardial adipose tissue inflammation can cause the distinctive pattern of cardiovascular disorders seen in psoriasis. Am J Med 2020;133:267-72.

27. Playford MP, Dey AK, Zierold C, Joshi AA, Blocki F, Bonelli F, et al. Serum active $1,25(\mathrm{OH}) 2 \mathrm{D}$, but not inactive $25(\mathrm{OH}) \mathrm{D}$ vitamin $\mathrm{D}$ levels are associated with cardiometabolic and cardiovascular disease risk in psoriasis. Atherosclerosis 2019;289:44-50.

28. Ergun T, Yazici V, Yavuz D, Seckin-Gencosmanoglu D, Ozen G, Salman A, et al. Advanced glycation end products, a potential link between psoriasis and cardiovascular disease: a case-control study. Indian J Dermatol 2019;64:201-6.

29. Pietrzak A, Chabros P, Grywalska E, Kicinski P, Pietrzak-Franciszkiewicz K, Krasowska D, et al. Serum lipid metabolism in psoriasis and psoriatic arthritis: an update. Arch Med Sci 2019;15:369-75.

30. Sorokin AV, Kotani K, Elnabawi YA, Dey AK, Sajja AP, Yamada S, et al. Association between oxidation-modified lipoproteins and coronary plaque in psoriasis. Circ Res 2018;123:1244-54.

31. Blegvad C, Nybo Andersen AM, Adam A, Zachariae C, Skov L. Psoriasis as a predictor of cardiometabolic comorbidity in women: a study based on the Danish National Birth Cohort. Acta Derm Venereol 2019;99:274-8.

32. Dickison P, Peek JJ, Swain G, Smith SDD. Non-invasive measurements to stratify cardiovascular disease risk in psoriasis patients. Aust J Gen Pract 2018;47:299-304.

33. Fernandez-Armenteros JM, Gomez-Arbones X, Buti-Soler M, BetriuBars A, Sanmartin-Novell V, Ortega-Bravo M, et al. Psoriasis, metabolic syndrome and cardiovascular risk factors: a population-based study. J Eur Acad Dermatol Venereol 2019;33:128-35.

34. Lloyd-Jones DM, Wilson PW, Larson MG, Beiser A, Leip EP, D'Agostino RB, et al. Framingham risk score and prediction of lifetime risk for coronary heart disease. Am J Cardiol 2004;94:20-4.

35. Akosah KO, Schaper A, Cogbill C, Schoenfeld P. Preventing myocardial infarction in the young adult in the first place: how do the National Cholesterol Education Panel III guidelines perform? J Am Coll Cardiol 2003;41:1475-9. 
36. Fernandez-Torres R, Pita-Fernandez S, Fonseca E. Psoriasis and cardiovascular risk: assessment by different cardiovascular risk scores. J Eur Acad Dermatol Venereol 2013;27:1566-70.

37. Koku Aksu AE, Saracoglu ZN, Metintas S, Sabuncu I, Cetin Y. Age and gender differences in Framingham risk score and metabolic syndrome in psoriasis patients: a cross-sectional study in the Turkish population. Anatol J Cardiol 2017;17:66-72.

38. Gyldenlove M, Jensen P, Linneberg A, Thyssen JP, Zachariae C, Hansen PR, et al. Psoriasis and the Framingham risk score in a Danish hospital cohort. Int J Dermatol 2014;53:1086-90.

39. Navarini L, Margiotta DP, Caso F, Currado D, Tasso M, Angeletti S, et al. Performances of five risk algorithms in predicting cardiovascular events in patients with psoriatic arthritis: an Italian bicentric study. PLoS One 2018;13:e0205506.

40. El-Mongy S, Fathy H, Abdelaziz A, Omran E, George S, Neseem N, et al. Subclinical atherosclerosis in patients with chronic psoriasis: a potential association. J Eur Acad Dermatol Venereol 2010;24:661-6.

41. Gonzalez-Cantero A, Gonzalez-Cantero J, Sanchez-Moya AI, PerezHortet C, Arias-Santiago S, Schoendorff-Ortega C, et al. Subclinical atherosclerosis in psoriasis: usefulness of femoral artery ultrasound for the diagnosis, and analysis of its relationship with insulin resistance. PLoS One 2019;14:e0211808.

42. Piaserico S, Osto E, Famoso G, Montisci R, De Michieli L, Zanetti I, et al. Long-term prognostic value of coronary flow reserve in psoriasis patients. Atherosclerosis 2019;289:57-63.

43. Elnabawi YA, Oikonomou EK, Dey AK, Mancio J, Rodante JA, Aksentijevich M, et al. Association of biologic therapy with coronary inflammation in patients with psoriasis as assessed by perivascular fat attenuation index. JAMA Cardiol 2019;4:885-91.

44. Gorga E, Scodro M, Valentini F, D'Ortona R, Arisi M, Sciatti E, et al. Echocardiographic evaluation of diastolic dysfunction in young and healthy patients with psoriasis: a case-control study. Monaldi Arch Chest Dis 2018;88:934.

45. Staniak HL, Bittencourt MS, de Souza Santos I, Sharovsky R, Sabbag C, Goulart AC, et al. Association between psoriasis and coronary calcium score. Atherosclerosis 2014;237:847-52.

46. Rueda-Gotor J, Llorca J, Corrales A, Parra JA, Portilla V, Genre F, et al. Cardiovascular risk stratification in axial spondyloarthritis: carotid ultrasound is more sensitive than coronary artery calcification score to detect high-cardiovascular risk axial spondyloarthritis patients. Clin Exp Rheumatol 2018;36:73-80.

47. Mehta NN, Yu Y, Saboury B, Foroughi N, Krishnamoorthy P, Raper A, et al. Systemic and vascular inflammation in patients with moderate to severe psoriasis as measured by [18F]-fluorodeoxyglucose positron emission tomography-computed tomography (FDG-PET/CT): a pilot study. Arch Dermatol 2011;147:1031-9.

48. Rose S, Sheth NH, Baker JF, Ogdie A, Raper A, Saboury B, et al. A comparison of vascular inflammation in psoriasis, rheumatoid arthritis, and healthy subjects by FDG-PET/CT: a pilot study. Am J Cardiovasc Dis 2013;3:273-8.

49. Youn SW, Kang SY, Kim SA, Park GY, Lee WW. Subclinical systemic and vascular inflammation detected by (18) F-fluorodeoxyglucose positron emission tomography/computed tomography in patients with mild psoriasis. J Dermatol 2015;42:559-66.

50. Shahidi-Dadras M, Niknezhad N, Niknejad N, Zargari O. Can serum level of N-terminal pro B-type natriuretic peptide be used in patients with psoriasis as a predictor of cardiovascular disease? Dermatol Ther 2019;32:e12865.

51. Curco N, Barriendos N, Barahona MJ, Arteaga C, Garcia M, Yordanov $\mathrm{S}$, et al. Factors influencing cardiometabolic risk profile in patients with psoriasis. Australas J Dermatol 2018;59:e93-8.

52. Kotwica T, Relewicz J, Rojek A, Tupikowska-Marzec M, Kabaj M, Karolko B, et al. Role of galectin-3 in subclinical myocardial impairment in psoriasis. J Eur Acad Dermatol Venereol 2019;33:136-42.

53. Libby P, Ridker PM, Hansson GK; Leducq Transatlantic Network on Atherothrombosis. Inflammation in atherosclerosis: from pathophysiology to practice. J Am Coll Cardiol 2009;54:2129-38.

54. Micha R, Imamura F, Wyler von Ballmoos M, Solomon DH, Hernan MA, Ridker PM, et al. Systematic review and meta-analysis of methotrexate use and risk of cardiovascular disease. Am J Cardiol 2011;108: 1362-70.

55. Prodanovich S, Ma F, Taylor JR, Pezon C, Fasihi T, Kirsner RS. Methotrexate reduces incidence of vascular diseases in veterans with psoriasis or rheumatoid arthritis. J Am Acad Dermatol 2005;52:262-7.

56. Vena GA, Vestita M, Cassano N. Psoriasis and cardiovascular disease. Dermatol Ther 2010;23:144-51.

57. Casserly CM, Stange KC, Chren MM. Severe megaloblastic anemia in a patient receiving low-dose methotrexate for psoriasis. J Am Acad Dermatol 1993;29:477-80.

58. Lan CC, Ko YC, Yu HS, Wu CS, Li WC, Lu YW, et al. Methotrexate reduces the occurrence of cerebrovascular events among Taiwanese psoriatic patients: a nationwide population-based study. Acta Derm Venereol 2012;92:349-52.

59. Balanescu AR, Bojinca VC, Bojinca M, Donisan T, Balanescu SM. Cardiovascular effects of methotrexate in immune-mediated inflammatory diseases. Exp Ther Med 2019;17:1024-9.

60. Russell G, Graveley R, Seid J, al-Humidan AK, Skjodt H. Mechanisms of action of cyclosporine and effects on connective tissues. Semin Arthritis Rheum 1992;21(6 Suppl 3):16-22.

61. Colombo MD, Cassano N, Bellia G, Vena GA. Cyclosporine regimens in plaque psoriasis: an overview with special emphasis on dose, duration, and old and new treatment approaches. ScientificWorldJournal 2013;2013:805705.

62. Wakkee M, Thio HB, Prens EP, Sijbrands EJ, Neumann HA. Unfavorable cardiovascular risk profiles in untreated and treated psoriasis patients. Atherosclerosis 2007;190:1-9.

63. Pietrzak A, Bartosinska J, Chodorowska G, Szepietowski JC, Paluszkiewicz P, Schwartz RA. Cardiovascular aspects of psoriasis: an updated review. Int J Dermatol 2013;52:153-62.

64. Hugh J, van Voorhees AS, Nijhawan RI, Bagel J, Lebwohl M, Blauvelt A, et al. From the Medical Board of the National Psoriasis Foundation: the risk of cardiovascular disease in individuals with psoriasis and the potential impact of current therapies. J Am Acad Dermatol 2014;70:168-77.

65. Stern RS, Fitzgerald E, Ellis CN, Lowe N, Goldfarb MT, Baughman $\mathrm{RD}$. The safety of etretinate as long-term therapy for psoriasis: results of the etretinate follow-up study. J Am Acad Dermatol 1995;33:44-52.

66. Robinson KP, Chan JJ. Colchicine in dermatology: a review. Australas J Dermatol 2018;59:278-85.

67. Sator P. Safety and tolerability of adalimumab for the treatment of 
psoriasis: a review summarizing 15 years of real-life experience. Ther Adv Chronic Dis 2018;9:147-58.

68. Boehncke S, Salgo R, Garbaraviciene J, Beschmann H, Hardt K, Diehl $\mathrm{S}$, et al. Effective continuous systemic therapy of severe plaque-type psoriasis is accompanied by amelioration of biomarkers of cardiovascular risk: results of a prospective longitudinal observational study. J Eur Acad Dermatol Venereol 2011;25:1187-93.

69. Mehta NN, Shin DB, Joshi AA, Dey AK, Armstrong AW, Duffin KC, et al. Effect of 2 psoriasis treatments on vascular inflammation and novel inflammatory cardiovascular biomarkers: a randomized placebo-controlled trial. Circ Cardiovasc Imaging 2018;11:e007394.

70. Rask L, Anundi H, Fohlman J, Peterson PA. The complete amino acid sequence of human serum retinol-binding protein. Ups J Med Sci 1987;92:115-46.

71. Pina T, Armesto S, Lopez-Mejias R, Genre F, Ubilla B, Gonzalez-Lopez MA, et al. Anti-TNF- $\alpha$ therapy improves insulin sensitivity in non-diabetic patients with psoriasis: a 6-month prospective study. J Eur Acad Dermatol Venereol 2015;29:1325-30.

72. Marra M, Campanati A, Testa R, Sirolla C, Bonfigli AR, Franceschi C, et al. Effect of etanercept on insulin sensitivity in nine patients with psoriasis. Int J Immunopathol Pharmacol 2007;20:731-6.

73. Chiricozzi A, Gisondi P, Girolomoni G. The pharmacological management of patients with comorbid psoriasis and obesity. Expert Opin Pharmacother 2019;20:863-72.

74. Uyemura K, Demer LL, Castle SC, Jullien D, Berliner JA, Gately MK, et al. Cross-regulatory roles of interleukin (IL)-12 and IL-10 in atherosclerosis. J Clin Invest 1996;97:2130-8.

75. Lee WK, Kim BS. Effects of ustekinumab on systemic and vascular inflammation assessed by 18F-FDG PET/CT in Korean patients with moderate to severe psoriasis. J Am Acad Dermatol 2017;76(6 Suppl 1):AB110.

76. Langley R, Valdes J, Gordon K, Papp K. Long-term safety and efficacy of ABT-874 for the treatment of moderate to severe psoriasis: interim analysis from an open-label extension study. J Am Acad Dermatol 2011;64(2 Suppl 1):AB148.

77. Van de Kerkhof PC, Griffiths CE, Reich K, Leonardi CL, Blauvelt A, Tsai TF, et al. Secukinumab long-term safety experience: a pooled analysis of 10 phase II and III clinical studies in patients with moderate to severe plaque psoriasis. J Am Acad Dermatol 2016;75:83-98.

78. Frieder J, Kivelevitch D, Menter A. Secukinumab: a review of the antiIL-17A biologic for the treatment of psoriasis. Ther Adv Chronic Dis 2018;9:5-21.

79. Egeberg A, Wu JJ, Korman N, Solomon JA, Goldblum O, Zhao F, et al. Ixekizumab treatment shows a neutral impact on cardiovascular parameters in patients with moderate-to-severe plaque psoriasis: Results from UNCOVER-1, UNCOVER-2, and UNCOVER-3. J Am Acad Dermatol 2018;79:104-9.

80. Strober B, Eichenfield L, Armstrong A, Gottlieb A, Lin T, Israel R. Overview of adverse cardiovascular events in the brodalumab psoriasis studies. J Am Acad Dermatol 2017;76(6 Suppl 1):AB186.

81. Reich K, Papp KA, Armstrong AW, Wasfi Y, Li S, Shen YK, et al. Safety of guselkumab in patients with moderate-to-severe psoriasis treated through 100 weeks: a pooled analysis from the randomized VOYAGE 1 and VOYAGE 2 studies. Br J Dermatol 2019;180:1039-49.

82. Ridker PM, MacFadyen JG, Everett BM, Libby P, Thuren T, Glynn RJ, et al. Relationship of C-reactive protein reduction to cardiovascular event reduction following treatment with canakinumab: a secondary analysis from the CANTOS randomised controlled trial. Lancet 2018;391:319-28.

83. Tsai YC, Tsai TF. Anti-interleukin and interleukin therapies for psoriasis: current evidence and clinical usefulness. Ther Adv Musculoskelet Dis 2017;9:277-94.

84. Saurat JH, Stingl G, Dubertret L, Papp K, Langley RG, Ortonne JP, et al. Efficacy and safety results from the randomized controlled comparative study of adalimumab vs. methotrexate vs. placebo in patients with psoriasis (CHAMPION). Br J Dermatol 2008;158:558-66.

85. Guenther LC, Kunynetz R, Lynde CW, Sibbald RG, Toole J, Vender R, et al. Acitretin use in dermatology. J Cutan Med Surg 2017;21(3_ suppl):2S-12S.

86. Borghi A, Corazza M, Bertoldi AM, Caroppo F, Virgili A. Low-dose acitretin in treatment of plaque-type psoriasis: descriptive study of efficacy and safety. Acta Derm Venereol 2015;95:332-6.

87. Chen K, Schenone AL, Borges N, Militello M, Menon V. Teaching an old dog new tricks: colchicine in cardiovascular medicine. Am J Cardiovasc Drugs 2017;17:347-60.

88. Papp KA, Sundaram M, Bao Y, Williams DA, Gu Y, Signorovitch JE, et al. Effects of briakinumab treatment for moderate to severe psoriasis on health-related quality of life and work productivity and activity impairment: results from a randomized phase III study. J Eur Acad Dermatol Venereol 2014;28:790-8.

89. Langley RG, Lebwohl M, Krueger GG, Szapary PO, Wasfi Y, Chan D, et al. Long-term efficacy and safety of ustekinumab, with and without dosing adjustment, in patients with moderate-to-severe psoriasis: results from the PHOENIX 2 study through 5 years of follow-up. Br J Dermatol 2015;172:1371-83.

90. Nemoto O, Hirose K, Shibata S, Li K, Kubo H. Safety and efficacy of guselkumab in Japanese patients with moderate-to-severe plaque psoriasis: a randomized, placebo-controlled, ascending-dose study. Br J Dermatol 2018;178:689-96.

91. Prinz JC, Puig L, Girolomoni G. Treatment of psoriasis with etanercept: the typical patient profile. J Eur Acad Dermatol Venereol 2016; 30:1092-9.

92. Burness CB, McKeage K. Adalimumab: a review in chronic plaque psoriasis. Drugs 2015;75:2119-30.

93. Tausend W, Downing C, Tyring S. Systematic review of interleukin-12, interleukin-17, and interleukin-23 pathway inhibitors for the treatment of moderate-to-severe chronic plaque psoriasis: ustekinumab, briakinumab, tildrakizumab, guselkumab, secukinumab, ixekizumab, and brodalumab. J Cutan Med Surg 2014;18:156-69.

94. Mansouri B, Kivelevitch D, Campa M, Menter A. Palmoplantar pustular psoriasis unresponsive to the interleukin-1 $\beta$ antagonist canakinumab. Clin Exp Dermatol 2016;41:324-6.

95. Fiolet AT, Nidorf SM, Mosterd A, Cornel JH. Colchicine in stable coronary artery disease. Clin Ther 2019;41:30-40.

96. Nidorf SM, Eikelboom JW, Budgeon CA, Thompson PL. Low-dose colchicine for secondary prevention of cardiovascular disease. J Am Coll Cardiol 2013;61:404-10.

97. Weger W. Current status and new developments in the treatment of psoriasis and psoriatic arthritis with biological agents. Br J Pharmacol 2010;160:810-20. 
98. Ronholt K, Iversen L. Old and new biological therapies for psoriasis. Int J Mol Sci 2017;18:2297.

99. Rungapiromnan W, Yiu ZZ, Warren RB, Griffiths CE, Ashcroft DM. Impact of biologic therapies on risk of major adverse cardiovascular events in patients with psoriasis: systematic review and meta-analysis of randomized controlled trials. Br J Dermatol 2017;176:890-901.

100. Pina T, Genre F, Lopez-Mejias R, Armesto S, Ubilla B, Mijares V, et al. Anti-TNF- $\alpha$ therapy reduces retinol-binding protein 4 serum levels in non-diabetic patients with psoriasis: a 6-month prospective study. J Eur Acad Dermatol Venereol 2016;30:92-5.

101. Ridker PM, Everett BM, Thuren T, MacFadyen JG, Chang WH, Ballantyne C, et al. Antiinflammatory therapy with canakinumab for atherosclerotic disease. N Engl J Med 2017;377:1119-31.

102. Choudhury RP, Birks JS, Mani V, Biasiolli L, Robson MD, L'Allier PL, et al. Arterial effects of canakinumab in patients with atherosclerosis and type 2 diabetes or glucose intolerance. J Am Coll Cardiol 2016;68: 1769-80.

103. Kimball AB, Gladman D, Gelfand JM, Gordon K, Horn EJ, Korman NJ, et al. National Psoriasis Foundation clinical consensus on psoria- sis comorbidities and recommendations for screening. J Am Acad Dermatol 2008;58:1031-42.

104. Dauden E, Castaneda S, Suarez C, Garcia-Campayo J, Blasco AJ, Aguilar MD, et al. Integrated approach to comorbidity in patients with psoriasis. Actas Dermosifiliogr 2012;103 Suppl 1:1-64.

105. Eder L, Harvey P, Chandran V, Rosen CF, Dutz J, Elder JT, et al. Gaps in diagnosis and treatment of cardiovascular risk factors in patients with psoriatic disease: an international multicenter study. J Rheumatol 2018;45:378-84.

106. Semb AG, Rollefstad S. Optimization of CVD prevention in psoriatic arthritis. Nat Rev Rheumatol 2018;14:323-4.

107. Phan C, Touvier M, Kesse-Guyot E, Adjibade M, Hercberg S, Wolkenstein $\mathrm{P}$, et al. Association between Mediterranean anti-inflammatory dietary profile and severity of psoriasis: results from the NutriNetSante cohort. JAMA Dermatol 2018;154:1017-24.

108. Molina-Leyva A, Cuenca-Barrales C, Vega-Castillo JJ, Ruiz-Carrascosa JC, Ruiz-Villaverde R. Adherence to Mediterranean diet in Spanish patients with psoriasis: cardiovascular benefits? Dermatol Ther 2019;32:e12810 